\title{
Design and Implementation of Underground Mining Safety Production Management System
}

\author{
Jun Luo \\ Civil and Environmental Engineering School, University of Science and Technology \\ Beijing, No.30,XueYuan Road, Haidian District, Beijing, 100083 \\ luojun_68@126.com
}

\begin{abstract}
In this paper, Underground Mining Safety Production Management System based on the $4 A$ idea has been put forward. Firstly, the safety status assessment and accident early warning indicator hierarchy has been established based on the analysis of the safety indicator in underground mining operation. Secondly, aimed at the hierarchy that established, the method for assessing it has been researched by using Fuzzy Analytical Hierarchy Process and. Thirdly, from the actual demand of safety management, the logic and architecture of Underground Mining Safety Production Management System has been designed. By using, java and SQL Server, the system, which contains the hierarchy and assessment method mentioned above, has been realized and also has been applied to two iron mine successfully. The application of the system not only improves the information level and systematic of mining safety management, but also improves the efficiency. Ultimately the purpose of reducing loss and improving benefit has been reached.
\end{abstract}

Keywords: mine, state evaluation, early warning, safety and accident management, information system

\section{Introduction}

Recent years, development of mining production is very fast, each step of the production task is very heavy. Meanwhile it brings a higher requirement to the safety of production. Mine safety production situation in our country maintains the overall stability, but accident decreasing rate decreased slower compared to previous years. Accident-prone trend has not been effectively curbed, production safety situation is still grim. The fact that large number of unsafe factors and many kind of hazards has brought certain difficulties to Safety production management and finally affected the performance of safety production.

With the development of mining systems engineering, computer and internet technology has gradually been applied into the area of mine management. Many enterprises have developed management information systems that cover geodesy, design, planning, equipment, inventory, marketing, accounting, and personnel work. Compared to the information management of the areas that mentioned above, though considerable progress has been made in the theory and technology of production safety management, the safety management is still on the level of localization and a lack of systematic. Also, the low level of safety information management of mining production cannot meet the developing requirements of mine information management $[1,2]$.

Taking the view of systematic and closed-loop management, the corresponding mine production safety accident management hierarchy and assessment method according to the 
actual condition of mines has been set up. By using JAVA language and SQL Server database, the underground mining safety production management system has been developed and can provide decision support for safety management.

\section{System Design Concepts and Theoretical Basis}

\subsection{System Design Goal}

In terms of design, this study proposed to build mining underground accident management information system. Through systematic research, to realize systematization standardization and digital management of mine production safety accidents information, collect mine production safety information data, reduce the strength of production safety management, enhance degree of safety information sharing, improve the efficiency of construction safety supervision, optimize the business workflow, complete production safety analysis and accident early warning, provide decision support for the leadership, improve the ability of accident prevention and control in the process of construction. Through the implementation of the system, leaders and personnel anywhere with proper privileges anybody can login in to the system at anytime to fulfill anything this system covers, so as to provide what we called " $4 \mathrm{~A}$ " service [3].

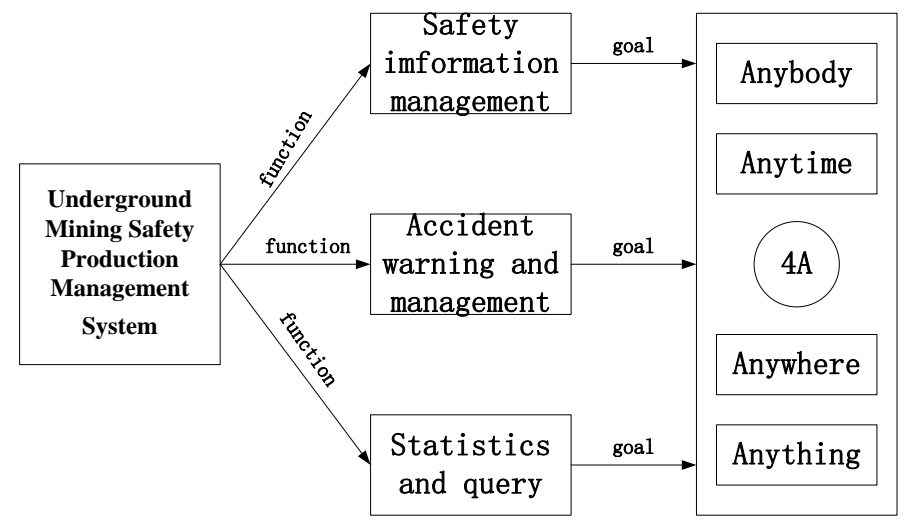

Figure 1. The Design Target of the System

\subsection{System Design Principle}

According to the overall goal of the system design, follow the ideas of information centralization, integration and system integration, use advanced, mature, economic, applicable, reliable, proactive technology, follow the "unified leadership, unified planning, unified standard, unified resource management" thinking, in the process of system design, we need to follow the following principles:

(1)Simple operation

System uses graphical interface with intuitive operation. At the same time, it can provide online help and instructions, the user can simply complete all operations.

(2)Applicability

System makes fully analysis of user needs in order to establish a system to satisfy the needs of the actual work. System is more close to the actual needs of the work, to solve safety problems in the practical work

(3)Ease maintenance

Use standard software development model and normalized design method, design reasonable of the database, take structural design in the development and module division of 
the system. Reduces the coupling between modules to ensure that the program is easy to maintain and modify.

(4)Reusability

Guarantees that the system can make full use of existing resources when upgrading.

(5)System reliability

System can not only meet the demands under normal conditions, but also in all kinds of abnormal cases, can act appropriately.

\subsection{Safety Status Assessment and Accident Early Warning Hierarchy}

\subsubsection{Safety Status Assessment and Accident Early Warning Indicator Hierarchy}

This paper divides mining production into the following six units: mining, elevating, blasting, power supply, ventilation and drainage. We constructed underground mining accident early warning hierarchy from four aspects of personnel, management, equipment, and environment as Figure 2 shows [4, 5].

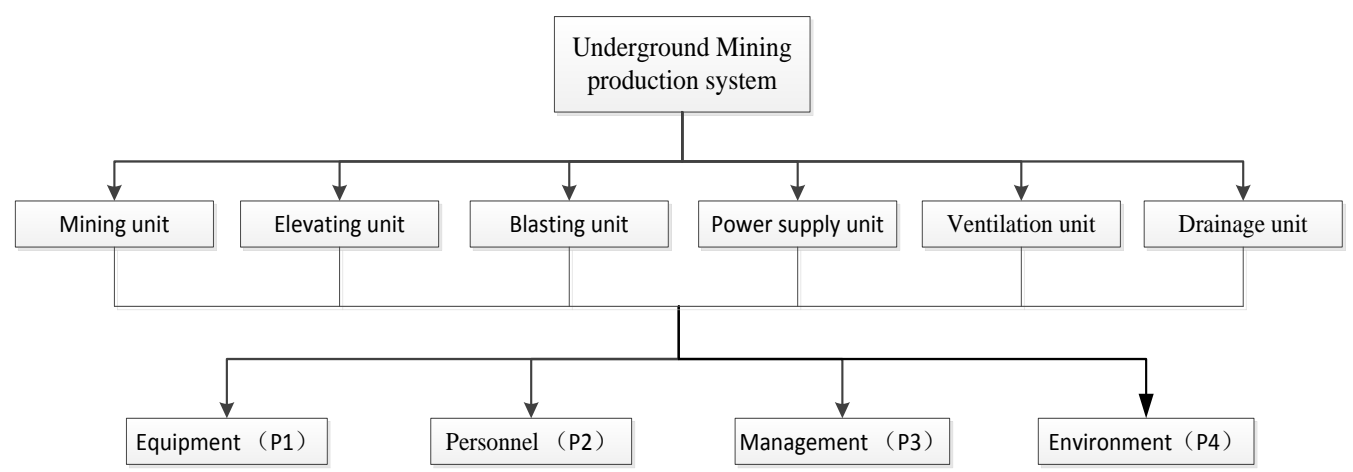

Figure 2. Safety Status Assessment and Accident Early Warning Indicator Hierarchy

Secondary indicators of equipment and personnel are included in this figure. Management and the environment status varies in different units. Use mining unit as an example to establish the system as shown below:

Table 1. Safety Indicators of Mining Unit

\begin{tabular}{|c|c|}
\hline $\begin{array}{c}\text { LEVEL } \\
\text { INDICATORS }\end{array}$ & SECONDARY INDICATORS \\
\hline \multirow{7}{*}{ personnel (P1) } & Personnel physiological state (S11) \\
\hline & Personnel mental state $(\mathrm{S} 12)$ \\
\hline & Single cumulative working hours (S13) \\
\hline & working experience (S14) \\
\hline & Professional skill level（S15） \\
\hline & Work error rate $(\mathrm{S} 16)$ \\
\hline & Staff safety consciousness $(\mathrm{S} 17)$ \\
\hline \multirow{2}{*}{ equipment (P2) } & Equipment usage (S21) \\
\hline & Equipment failure condition $(\mathrm{S} 22)$ \\
\hline
\end{tabular}




\begin{tabular}{|c|c|}
\hline & Equipment current production status (S23) \\
\hline & Equipment safety check is ok or not (S24) \\
\hline \multirow{7}{*}{$\begin{array}{l}\text { environment } \\
\text { (P3) }\end{array}$} & The reliability of the safe channel（S31） \\
\hline & The pros and cons of geological conditions (S32) \\
\hline & Rationality of support (S33) \\
\hline & Roof caving state $(\mathrm{S} 34)$ \\
\hline & field condition (S35) \\
\hline & The security of fall prevention facilities (S36) \\
\hline & Conductive material is bare or not (S37) \\
\hline \multirow{5}{*}{$\begin{array}{l}\text { management } \\
(\mathrm{P} 4)\end{array}$} & The rationality of mining technology (S41) \\
\hline & Robustness of safety management system (S42) \\
\hline & staff safety education is ok or not $(\mathrm{S} 43)$ \\
\hline & Completeness of safety inspection (S44) \\
\hline & safety training is complete or not $(\mathrm{S} 45)$ \\
\hline
\end{tabular}

\subsubsection{Safety State Assessment Method}

This paper uses Mining unit as an example to show the safety state assessment method of each unit [4-7].

(1)Personnel indicators

1) First of all, use the fuzzy analytic hierarchy process to calculate the weight of each secondary indicator.

(1) Establish optimization matrix $\mathrm{A}=\left(\mathrm{A}_{\mathrm{IJ}}\right)_{7 * 7}$

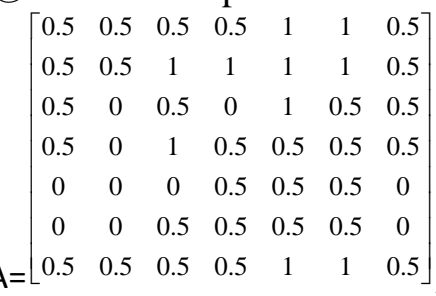
table 1 .

(2) transform the precedence relation matrix into fuzzy consistent matrix

(3) $\mathrm{B}=\left(\mathrm{B}_{\mathrm{IJ}}\right)_{7 * 7}$,

$\left[\begin{array}{ccccccc}0.5 & 0.4286 & 0.6071 & 0.5714 & 0.9286 & 0.6786 & 0.5 \\ 0.5714 & 0.5 & 0.6786 & 0.6429 & 0.7857 & 0.75 & 0.5714 \\ 0.3929 & 0.3214 & 0.5 & 0.4643 & 0.6071 & 0.5714 & 0.3929 \\ 0.4286 & 0.3571 & 0.5357 & 0.5 & 0.4643 & 0.6071 & 0.4286 \\ 0.0714 & 0.2143 & 0.3929 & 0.5357 & 0.5 & 0.4643 & 0.0714 \\ 0.3214 & 0.25 & 0.4286 & 0.3929 & 0.5357 & 0.5 & 0.3214 \\ 0.5 & 0.4286 & 0.6071 & 0.5714 & 0.9286 & 0.6786 & 0.5\end{array}\right]$

Each secondary indicators weight was calculated in the end:

$\mathrm{W}_{\mathrm{I}}=\{0.167365,0.099243,0.070352,0.316324,0.053451,0.125899,0.167365\}$ 。

2) The initial value of secondary indicators are all 100, then rating the secondary indicators according to the actual situation. Method is as follow:

(1) $\mathrm{S} 11$

S11 contains 3 factors, which are vision, hearing and physical fitness and each factor has 
a full mark of 100. The mark for Hearing and physical fitness can be get from examination report, and the mark of vision can be get as follow( $x$ is the value of vision):

$$
V(x)= \begin{cases}90+10 \times(x-5) & x \geq 5.0 \\ 90-100 \times(5-x) & 4.5 \leq x \leq 5 \\ 40-8 \times(4.5-x) & x<4.5\end{cases}
$$

The final mark of S11 is the average of 3 factors mark.

(3) S12、S14、S15、S17

For the four indicators, the input value is good 、 very good、 middle , general、 poor、very poor six levels. Very good is 100 points, good is 85 points, middle is 70 points, general is 60 points, poor is 50 points, very poor is 35 points.

(4) S13、S16

For S13,if the real work time is within 8 hours, the value is 100 points, when exceeds every one hour, deduct 10 points. When exceeds 4 hours, the value is 0 . For S16, when error rate is lower than $30 \%$, when adding one percent, the value deducts 1 point, when error rate is higher than $30 \%$ and lower than $60 \%$, when adding 0ne percent, the value deduct 2 points. When exceeds $60 \%$, the value is 0 .

3) Each secondary index score multiplied by their weights, the sum of the secondary indicator values forms the value of first level indicator.

(2)Equipment indicators

Choose the minimum value of all the secondary indicators as Equipment security status value. Determine the value of each secondary indicator as follow.

1) $\mathrm{S} 21$

Initial value of $\mathrm{S} 21$ is 100 , when a device is within its durable years, each year deduct its durable years score by 40 . When exceed the durable years, each year deduct its durable years score by 80 . Then we can get the safety status value of $\mathrm{S} 21$

2)S22

The initial value of $\mathrm{S} 22$ is 100 . When the interval from the last maintenance time is within the mean repair time, the status value is $100-20 *$ (interval from last maintenance)/(mean repair time). When the interval from the last maintenance time is out of the mean repair time, the status value is $100-40^{*}$ (interval from last maintenance)/(mean repair time).

3)S23、S24

The input value of S23 S24 is good、very good、middle、general、poor、very poor six levels. Very good is 100 points, good is 85 points, middle is 70 points, general is 60 points, poor is 50 points, very poor is 35 points.

(3)Environment indicators

For every secondary indicator of environment, the input value is good、very good、 middle、general、poor、very poor six levels. Very good is 100 points, good is 85 points, middle is 70 points, general is 60 points, poor is 50 points, very poor is 35 points. The value of environment is the minimum value of all these secondary indicators.

(4)Management indicators

The assessment method of management indicator is as the same as environment indicators. 


\section{System Structure Design}

\subsection{Function Requirements Analysis}

The system is designed to achieve mine production safety information management. Combined with the survey results and advanced research in related fields, the system should have the following function:

(1)user management.

Realization of user information management, such as password and right management.

(2)information management

The system should provide operations on all kinds of safety information, which contain inputting, editing and searching.

(3)safety status assessment and early warning

The system should be able to achieve the assessing of security status of each mining production unit and provide early warning.

(4)accident management

The system should be able to realize the digital management of historical accident information.

(5)statistical analysis

The system should achieve the comparison and trend statistics of historical safety data, and generate the statistical charts.

\subsection{System Logical Structure}

According to the functional requirements and characteristics of the modules of this system, this manuscript divide the system into 4 layers as data layer, model layer, supporting layer and application layer, as Figure 3 shows:

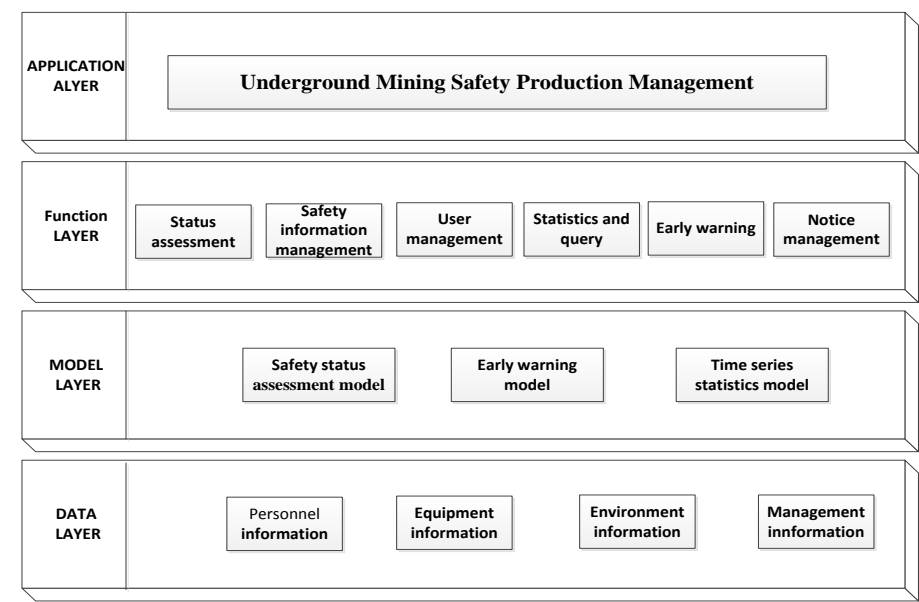

Figure 3. System Logical Structure

System starts from underground minimum individuals of personnel and equipment during the production process, through assessment of the personnel equipment integrated with management of all aspects, such as environmental management to implement the whole process of mine production safety early warning, and take corresponding measures according to the results of early warning, then the system will feedback the result so as to implement close-loop management. 


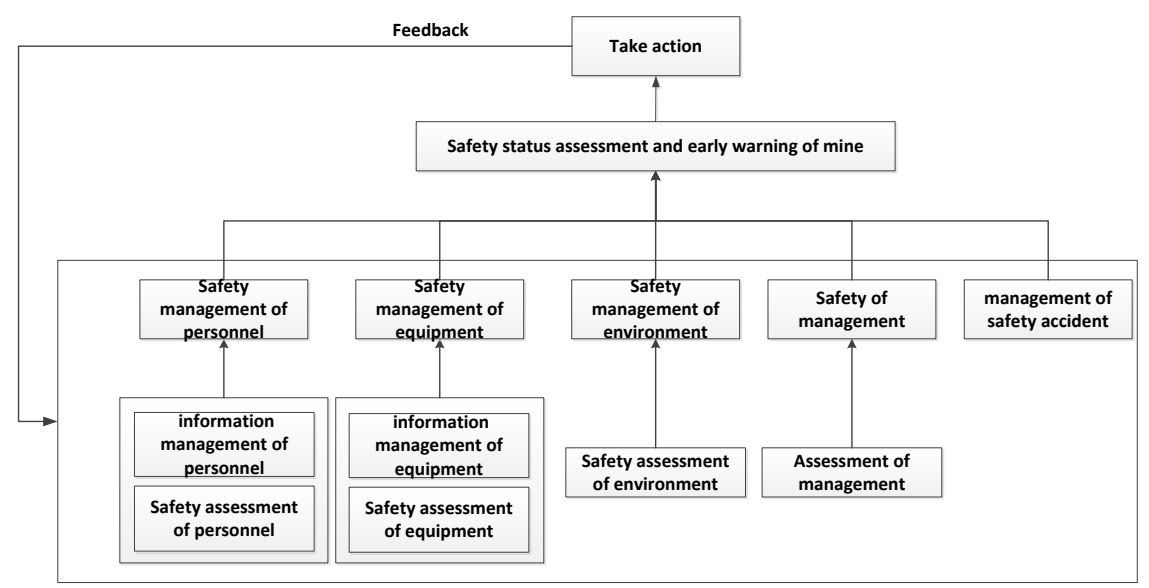

Figure 4. System Principle Diagram

\subsection{Development Method}

The System adopts B/S (browser/server) mode. By using JAVA language and SQL Server 2005 as developing language and database, the system has been developed on the platform of eclipse.

\subsection{System Functional Structure}

Underground mining production accident management information system is geared to the needs of mine production and management of integrated information systems. It mainly realize underground safety information management of each work unit. Then it evaluates the security status of each unit according to certain safety assessment model. Finally, it will demonstrate the information after statistics and analysis.

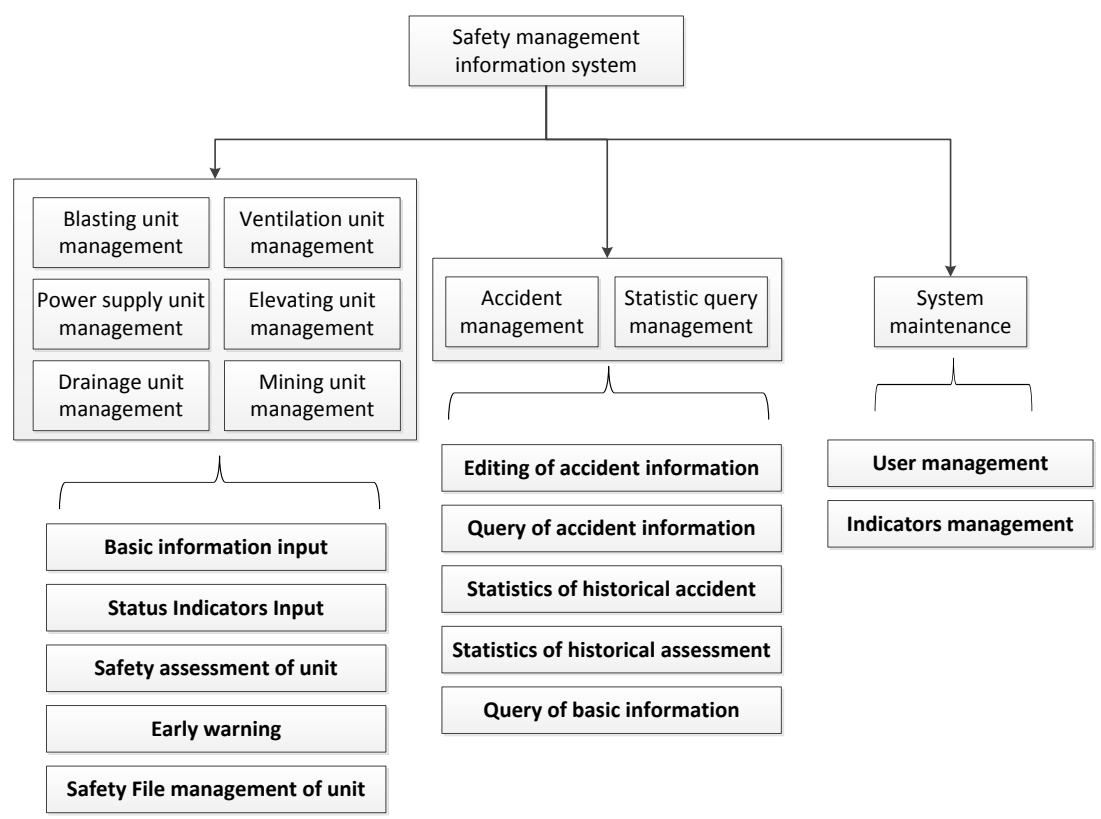

Figure 5. System Functional Structure 


\section{System Application}

This system has been successfully applied to multiple iron mine production safety management and has effectively completed the all kinds of underground safety information management and safety state evaluation work, provides a strong guarantee to reduce the occurrence of accidents in mines.

\section{Conclusion}

This manuscript starts from the perspective of system, analyzed and designed the logical structure, physical structure and functional structure of the system based on actual production safety accident management requirements and conducted the development. The research formed safety production accident management system with basic information management, early-warning indicator safety state evaluation, status early warning alarm modules which well supported underground mine safety production.

\section{References}

[1] D.-L. Shao and Z.-H. Qiu, "Development status and new trends of the mining systems engineering", vol. 17, no. 9, (2008).

[2] Y.-T. Wang and Z.-X. Bo, "Principle and application of modern Mining System Engineering", vol. 5, no. 6, (2007).

[3] Y.-H. Wang, J. Luo and C.-C. Zhang, "Design of Safety-Risk-Management Information System for Urban Rail Transit Construction Based on GIS", vol. 10, no. 4, (2010).

[4] M.-K. Tang, Y.-C. Zhu and H. Liu, "Identification and Control of Major Hazard in Metallurgical Mine", vol. 33 , no. 6, (2004).

[5] H.-W. Deng, "Present, The research of mine dangerous source model in debating and model index system", Chang Sha Institute of Mine Research, (2005).

[6] J.-F. Zhang, "Research on the safety assessment and early warning of underground mine", Wuhan University of Science and Technology, (2009).

[7] Z.-Y. Chen, "Safety analysis and assessment of mine production system", Wuhan University of Science and Technology, (2009).

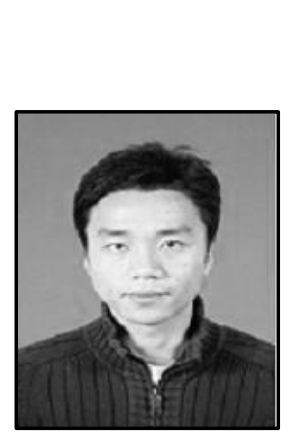

\section{Author}

Jun Luo. He received his M.Sc. in Beijing Jiaotong University (2010). Now he is studying for PhD in University of Science and Technology Beijing. Since 2010, his current research interests include different aspects of mining safety management and traffic construction safety management. 